\title{
Inductively-Coupled Plasma Mass Spectrometry
}

National Cancer Institute

\section{Source}

National Cancer Institute. Inductively-Coupled Plasma Mass Spectrometry. NCI

Thesaurus. Code C62328.

A mass spectrometry technique that uses inductively-coupled plasma generated from argon gas to atomize and ionize a sample. The resulting ions are separated and analyzed using a mass spectrometer. 